\title{
Device to Subject Relationship Domain
}

National Cancer Institute

\section{Source}

National Cancer Institute. Device to Subject Relationship Domain. NCI Thesaurus. Code C102620.

A subject domain utilized for the submission of information encompassing and representing data, vocabulary or records related to device to subject relationship. 